\title{
Psicopatologia, fenomenologia e cultura: a contribuição de Arthur Tatossian
}

\author{
Virginia Moreira
}

Pesquisas transculturais mostram que a psicopatologia tem tanto características universais, no que se refere a seus aspectos biológicos, quanto singulares, no que diz respeito a seus aspectos históricos e culturais (Sartorius, 1983; Kleinman \& Good, 1985; Schumaker, 1996, 2001; Morris, 1998; Marsella \& White, 1982; Marsella \& Yamada, 2000; Tatossian, 1997; Tellenbach, 1969; Moreira, 2000; Moreira \& Coelho, 2001). Este mesmo fato é observado por psiquiatras e psicólogos clínicos que trabalham com pacientes provenientes de distintas culturas (Natan, 1999; Cuéllar \& Paniagua, 2000).

Diante de tantas evidências quanto à importância da cultura na etiologia da psicopatologia, não cabe dúvida, como assinalam Marsella \& Yamada (2000), de que a hegemonia atual do modelo biomédico é uma questão de poder: “... não é segredo que nas últimas décadas a psiquiatria tem buscado extirpar-se de sua herança freudiana e reestabelecer-se como uma especialidade médica (p. 6). Tampouco é segredo que o uso indevido e massificado de psicofármacos, não pouco freqüente nos dias de hoje, pode acabar levando à produção social de toxicomanias, pelas vias da medicação psiquiátrica e do mercado de drogas pesadas, como assinala Birman (1999).

O fato é que uma abordagem da psicopatologia, em sua complexidade etiológica, necessita superar uma forma dualista de pensar, característica do mundo ocidental, para que os profis- 
sionais da área de saúde mental possam utilizar-se tanto dos relevantes progressos da psicofarmacologia nas últimas décadas quanto da atenta lente cultural, que nos proporcionam os estudos de cunho antropológico. Urge, de uma vez por todas, ir além de uma forma dualista, restritiva e pobre de pensar a psicopatologia, na qual sempre se toma unicamente uma perspectiva ou outra (no caso, a biologicista ou a culturalista) assumindo, definitivamente, a ambigüidade (no sentido merleaupontyano) do fenômeno psicopatológico (Moreira, 2001).

Ainda que em Maurice Merleau-Ponty, “o filósofo da ambigüidade”, se encontre, provavelmente, o ápice do rompimento das dicotomias na fenomenologia pela instauração da ambigüidade, estudiosos da psicopatologia podem também contar com uma contribuição mais recente da psiquiatria fenomenológica através da obra de Arthur Tatossian. Longe de pôr em dúvida a determinação biológica dos diversos quadros psicopatológicos (visão coerente com sua formação como médico neurologista e psiquiatra), os escritos de Tatossian, reunidos e publicados basicamente em dois volumes, evidenciam uma consistente e sistemática lente cultural na clínica psiquiátrica, o que faz com que sua abordagem da psicopatologia seja sabiamente ambígua.

Além do perfeito domínio da obra de Husserl, Heidegger, Kuhn, Minkowski, Binswanger e, evidentemente, Merleau-Ponty, entre outros, Tatossian usou como referência os trabalhos de Devereux, Kimura, Tellenbach e de inúmeros resultados de pesquisas transculturais que mostram variações evidentes nas manifestações psicopatológicas. No entanto, defende que não deve haver uma psiquiatria para cada cultura, mas uma única psiquiatria que seja "metacultural”, como propunha Devereux, e, para que isto seja possível, a cultura deve ser necessariamente parte inerente da psiquiatria. Esta perspectiva ambígua, profundamente impregnada nos escritos de Tatossian, é marca registrada na sua importante obra sobre psicopatologia, que influencia o pensamento de toda uma geração de psiquiatras e fenomenólogos clínicos franceses nestas duas últimas décadas, pelo menos. Nas palavras de Debray (1997),

... a psiquiatria clássica evitou regularmente a abordagem cultural, o acontecimento, o fato diversificado, para se refugiar sobre um promontório acadêmico - de onde, o humor depressivo, figuração elegante de um conjunto considerável de acontecimentos existenciais e biológicos. Mas a fenomenologia não teme aqui [refere-se ao livro Phénomenologie des psychoses] em reificar de forma rigorosa todo este conjunto que vai do equilíbrio biológico até às perspectivas impregnadas de tradições culturais. (p. 5)

Nascido em Marseille, em 1929, e filho de imigrantes armênios, Arthur Tatossian é descrito como tímido, introvertido e modesto, ainda que considerado um mestre por profissionais da área de saúde mental que tiveram a oportunidade de conviver com ele. Preocupou-se muito mais em estudar, clinicar e escrever do que em 
publicar seu pensamento. Isto explica o fato de que Phénomenologie des psychoses, redigido para o Congresso de Psiquiatria e Neurologia de Língua Francesa, realizado em 1979 em Angers, e as várias conferências proferidas ao longo de sua vida, além do seu reconhecido trabalho de doutoramento em medicina sobre um caso de esquizofrenia paranóide, tenham sido reunidos e reeditados apenas em 1997, no livro intitulado Psiquiatria fenomenológica, além do volume especial publicado pela Revista L'Art du Comprendre com a reedição de Phénomenologie des psychoses, tornando acessível à psicopatologia contemporânea este texto denso e límpido que fascinou toda uma geração (Debray, 1997).

As conferências de Tatossian sobre temáticas relacionadas à cultura e à psicopatologia testemunham uma explícita contribuição do âmbito da psiquiatria fenomenológica à psicopatologia:

... como gostava de mencionar Arthur Tatossian, a abordagem fenomenológica não pode se entender como um novo olhar integrado às outras abordagens psicopatológicas da psiquiatria. Ela é campo de experiência em si mesma e só pode ser validada por ela mesma. Ela é a atitude a "ver" o peso exato das coisas. É uma "lógica do mundo”, uma lógica natural. Esta lógica, esta evidência, não é mais do que intersubjetiva. A leitura fenomenológica que Arthur Tatossian propõe da psiquiatria não é uma explicação, mas um "ver” da experiência psiquiátrica. (Tatossian, J. \& Samuelian, 1997: 157)

A aguda compreensão da importância da experiência possibilitou a este fenomenólogo francês pensar a psicopatologia de forma ambígua, levando em conta tanto os aspectos biológicos quanto os culturais, não como contradições, mas como dimensões entrelaçadas de um mesmo fenômeno. Como ele mesmo constata em suas conferências sobre cultura e psicopatologia, a vivência da doença é a mesma em distintas culturas, mas a forma de sua expressão variará segundo o ambiente cultural em que ela se manifeste. E, como bem lembram Kleinman \& Good (1985), uma perspectiva antropológica que entende a cultura como a interseção do significado com a experiência é, sem dúvida, muito útil ao estudo da psicopatologia.

A obra de Arthur Tatossian integra a psicopatologia, a fenomenologia e a cultura, mas vai muito além, representando um momento importante no desenvolvimento do conhecimento da psicopatologia.

\section{Referências bibliográficas}

Aвоud, F. Health psychology in global perspective. Thousand Oaks: Sage, 1998.

Birman, J. A psicopatologia na pós-modernidade. As alquimias do mal-estar da atualidade. Revista Latinoamericana de Psicopatologia Fundamental, Ano 2, n.1, São Paulo, mar/1999, p. 25-49. 
Cuéllar, I. \& Paniagua, F. Multicultural mental health. San Diego: Academic Press, 2000.

MarSella, A. Socialcultural foundations of psychopathology: a pre-1970 historical overview. Transcultural Psychiatric Research and Review, 30, 1993, p. 97-142.

\& White, G. (eds.) Cultural conceptions of mental health and therapy. Boston: G. Reidel/Kluwer, 1982.

\& YAMADA, A.M. Culture and mental health: an introduction and overview of foundations, concepts and issues. In: Cuéllar, I. \& Paniagua, F. (ed.). Handbook of multicultural mental health. San Diego: Academic Press, 2000.

Moreira, V. Modos de constitución de la subjetividad: una perspectiva fenomenológica transcultural. Psykhe, vol. 8, n.1, 1999, p. 27-31.

Ideologia e psicopatologia: uma discussão fenomenológica transcultural. Revista Latinoamericana de Psicopatologia Fundamental, Ano 3, n. 4, São Paulo, dez/2000, p. 80-91.

. Más allá de la persona: hacia una psicoterapia fenomenológica mundana. Santiago: Universidad de Santiago de Chile, 2001.

\& Coelho, N. Phenomenology of body, time and space: a cross-cultural study Brazil-Chile, 2001. (no prelo)

Morris, D. B. Illness and culture in the postmodern age. USA: University of California Press, 1998.

Nathan, T. La influencia que cura. Buenos Aires: Fondo de Cultura Economica de Argentina, 1999.

Sartuorius, H. Trastornos depresivos en diferentes culturas. México: Organizacion Mundial de La Salud, 1983.

SchumaKeR, J. Understanding psychopatology: lessons from the developing world. In Psychology and developing world. Connecticut: Praeger, 1996.

Cultural cognition and depression. In — — W WARD, T. Cultural cognition and psychopathology. Westport: Praeger, 2001.

Tatossian, A. Psychiatrie phénomenologique. Paris: Acanthe, 1997.

Tellenbach, H. Estudios sobre la patogénesis de las perturbaciones psíquicas. México: Fondo de Cultura Económica, 1969.

La melancolía. Visión histórica del problema: endogeneidad, tipología, patogenía y clínica. Madrid: Morata (traducción de la $2^{\text {a }}$ edición), s/d.

Versão inicial recebida em fevereiro de 2001

Versão revisada recebida em agosto de 2001 